\title{
Cross-fertilisation between human-computer interaction and artificial intelligence
}

\author{
Christophe Kolski ${ }^{1}$, Guy André Boy ${ }^{2}$, Guy Melançon ${ }^{3}$, Magalie Ochs ${ }^{4}$ and Jean Vanderdonckt ${ }^{5}$ \\ ${ }^{1}$ LAMIH, Universite' de Valenciennes, France, e-mail: Christophe.Kolski@univ-valenciennes.fr \\ ${ }^{2} \mathrm{HCDI}$, Florida Institute of Technology, USA, e-mail: gboy@fit.edu \\ ${ }^{3}$ LaBRI, Universite' de Bordeaux, France, e-mail: Guy.Melancon@u-bordeaux.fr \\ ${ }^{4}$ LSIS, Aix-Marseille Université, France, e-mail: magalie.ochs@1sis.org \\ ${ }^{5}$ LiLab, UCL, Belgium, e-mail: jean.vanderdonckt@uclouvain.be
}

\begin{abstract}
Human-Computer Interaction (HCI) and Artificial Intelligence (AI) are two disciplines that followed parallel trajectories for about four decades. They also both complement each other and overlap in various problem-rich domains. This chapter is far from being exhaustive, but provides a representative story of how $\mathrm{HCI}$ and $\mathrm{AI}$ cross-fertilise each other since their inception. It reviews the following domains: intelligent user interfaces and more specifically conversational animated affective agents; capitalisation, formulation and use of ergonomic knowledge for the design and evaluation of interactive systems; synergy between visualisation and data mining.
\end{abstract}

\section{Introduction}

Goals of this chapter are to study the various interfaces between Human-Computer Interaction $^{1}(\mathrm{HCI})$ and Artificial Intelligence (AI), and to advocate their necessary association. AI purpose is to create and develop intelligent systems (i.e., systems

\footnotetext{
${ }^{1}$ The term "Human-Computer Interaction", still very much used, is shifting toward "HumanSystems Interaction" since we are developing "systems" that include both computing and physical things.
} 
that are capable to perceive, reason, act and learn by themselves). This fundamental objective led to the development of methods, techniques and tools that enabled systems to effectively perceive, reason, act and learn, within limited environments. Even if first results were limited, AI ambition and framework clearly lead to a longterm endeavor. For example, robotics made impressive progress. Most recent example is "Curiosity", the NASA robot that is currently exploring planet Mars. HCI is more focused on usability of new technology, promoting creativity and innovation. HCI always had shorter-term goals. We should note that remote Curiosity operations from the Earth cannot be performed without user interfaces based on solid HCI concepts and principles, more specifically regarding planning of its activities. In other words, NASA ground operators must have the best situation awareness of how Curiosity's instruments can be used and what are resources required for the various scheduled activities ${ }^{2}$.

It is useful to realise that both AI and HCI have to take into account the people who will be involved in the use of the technology being developed. On one side, AI attempts to mimic the human being and rationalise his or her behaviours to build various types of intelligent systems, including robots. On the other side, HCI attempts to understand the human being to better adapt machines to improve safety, efficiency and comfort experience. AI focuses on internal mechanisms of a rational intelligence. Instead, HCI focuses on fundamental phenomena of interaction among people and tools, which they created and use.

It is now obvious that $\mathrm{HCI}$ specialists use more AI techniques to improve interaction. They use machine learning to contextualise Web search for example. AI specialists need user interfaces appropriate to the use of intelligent systems. Humanrobot interaction is an excellent example of HCI-AI fusion. The writer, Isaac Asimov, provided his famous Three Laws of Robotics in 1941: “(Law 1) a robot may not injure a human being or, through inaction, allow a human being to come to harm; (Law 2) a robot must obey the orders given to it by human beings, except where such orders would conflict with the First Law; and (Law 3) a robot must protect its own existence as long as such protection does not conflict with the First or Second Law." [Asimov, 2008]. Here we find again the concepts of safety, efficiency and comfort fit for human-computer interaction.

This combination of $\mathrm{HCI}$ and $\mathrm{AI}$ is gradually emerging from increasing needs of meaning, knowledge, skills, experience? and finally common sense. The success of a new technology is often the product of an intelligent and meaningful integration of various methods, techniques and systems. AI provides tools for externally automating human behaviour, as well as creating new cognitive prostheses [Ford et al, 1997]. HCI provides tools for safer, more efficient and more comfortable human interaction with resulting technology. It is certainly more interesting to head toward a more comprehensive approach to systems design which incorporates both intelligence and interaction, taking into account the use of computer science and social sciences in concert to go to human-centred design [Boy, 2012].

\footnotetext{
${ }^{2} \mathrm{http} / /$ hci.arc.nasa.gov/mslice.html
} 
The second part of the chapter presents a design history and genesis of interfaces between HCI and AI. Intelligent user interfaces are presented in the third part. Among recent advances in the field, emotional embodied conversational agents will be presented in Part Four. Part Five is devoted to capitalisation, formalisation and use of ergonomic principles for the design and evaluation of interactive systems. Part Six is devoted to visualisation and data mining. The last part of the chapter concludes on cross-fertilisation between HCI and AI.

\section{History of interfaces between $\mathrm{HCI}$ and AI: a genesis}

$\mathrm{AI}$ and $\mathrm{HCI}$ are two branches of computer science. They are complementary disciplines that have different objectives and natures. AI is studying intelligent agents (i.e., any entity capable of perceiving, infer and act on its environment using its own knowledge). In 1955, John McCarthy named and defined AI as a scientific and technical discipline that supports the making of intelligent machines. HCI studies devices to be used for the control of and communication with a machine, or with other people through a machine. ACM SIGCHI provides the following definition ${ }^{3}$ : "Human-computer interaction is a discipline concerned with the design, evaluation and implementation of interactive computing systems for human use and with the study of major phenomena surrounding them." [Hewett et al, 1992].

It is certainly interesting to start talking about automatic control before talking about artificial intelligence. Although these two disciplines do not belong to the same scientific fields, they are continuous in the field of automation, this is to say in the industry. We automated transport aircraft since the nineteen-thirties. This type of automation enabled the implementation of analogue and then digital techniques to develop and use symbolic techniques and tools. Automation increasingly became a software engineering issue. For example, we observed the evolution of aircraft cockpits electronic equipment to computing equipment. In the nineteen-eighties, the Flight Management System (FMS) was introduced as an onboard database management system for commercial aircraft. It enabled freeing the aircrew from flight planning and navigation tasks. FMS includes necessary flight management intelligence that was previously the only ownership of pilots. Underlying methods were based on rule-based systems and trajectory optimisation. In the beginning, the FMS, as a computing system, was often more difficult to handle and manage than paper maps and documents. Intelligence was transferred to the machine with very little care about human-computer interaction with this new system, generating new types of human errors. The interface was complicated due technology limitations (it would not done the same today). Its use was difficult to learn and remember. In short, if automation was good, pilot-FMS interaction required a lot more work. We had to wait for more mature technology to get the type of user interface that we know today in the cockpit of the A380, for example. It is interesting to notice that this type

${ }^{3}$ ACM (Association for Computing Machinery)-SIGCHI (Special Interest Group on ComputerHuman Interaction). 
of cockpit is now called "interactive cockpit" not because of the interaction with systems' mechanical parts of the aircraft but with the onboard user interface that involves a pointing device and screens.

The term HCI includes the term "human". The human entity is difficult to identify, define and model. For a long time, the Human Factors and Ergonomics (HF\&E) community has addressed this issue [Woodson and Conover, 1964]. The human being can be characterised by various properties. Firstly, the human has a physical and physiological body (e.g., an issue that HF\&E experts have questioned since the end of World War II with the development of digital manikins). The biomechanical aspects, fatigue, age and other human factors have been and are still widely and deeply considered. Physical ergonomics was that we experienced in the early nineteen-eighties when we had to certify transport aircraft cockpits designed for two crewmen cockpits. We very quickly realised that physical and physiological ergonomics was not enough and was very limited with respect to the evaluation of new aircraft systems. We had to go to cognitive ergonomics in order to properly support analysis of information processing [Norman, 1986]. In addition, conventional automation techniques were not sufficient. HCI techniques addressing highly automated systems became the central focus of problems to be solved. HCI was entering the cockpit, as it made its entrance in areas of critical systems in the years that followed. At the time, we focused on information processing and that is why cognitive science has taken a considerable extent in the engineering community. Cognitive ergonomics and cognitive engineering have become key disciplines for the analysis, understanding, design and evaluation of modern human(s)-machine(s) systems. Cognition has become a central must [Card et al, 1983] [Hutchins, 1995] [Boy, 1998].

The cognitive approach then gave birth to an organisational point of view with the introduction of groupware and collaborative work (CSCW: Computer-Supported Cooperative Work) [Grudin, 1994]. For these HCI specialists, the human became a worker in an organisation. Computer science suddenly became a strong support to management and business. In the background, Internet was becoming more persistent, since Douglas Engelbart's work in the sixties until the advent of the World Wide Web in 1992 by Tim Burners Lee and his team at CERN in Geneva. The Web has really established a drastic practice change in modern societies. The human has gradually become "informavore" (term introduced by George Miller in 1983). Information sciences took this new object and topic. The main issue then became information management using the Web. HCI cooperated with AI to optimize and adapt information search to users [Bellot, 2011; Boy, 1991a]. The Web has become the Semantic Web [Berners-Lee et al, 2001] [Shadbolt et al, 2006], adding the intelligence of an universal librarian.

HCI evolution led us then to a new stage, that of social networks. The human becomes a social being for IT professionals in the field. The introduction of systems such as Google, Facebook, LinkedIn and Twitter led to the emergence of new practices. No need for structure, knowledge could be completely distributed, we could find them anywhere anytime. Research scientists and practitioners in sociology and anthropology came on stage to study this new type of environments. Interactions 
among people and systems are now inherently social but also emotional; human emotions can be both positive and negative facing an interactive system. Artificial intelligence of a system then also lies in its ability to manage the emotional aspects of interaction through interfaces capable of adapting to the social context and user's emotions. This research problem has created an IT research trend lying on the border between HCI and AI: affective computing [Picard, 1997].

Where are we today? Information technology development brought us a lot of techniques and tools. Certainly too many for us to be able to reasonably integrate them easily, with respect to our problems to solve. It is time to ask the question of meaning. What is making sense? We are going from the problem of knowing to the problem of being. That is why design (in the sense of integrated design and aesthetics) is increasingly becoming a necessity in engineering sciences, and computing in particular. The design approach to problem solving uses creativity rather than already-made, blocking and ultimately sterile procedures. What characterises our 21 st century society is certainly complexity. On this point, AI and HCI must get together to solve problems whose complexity is at the centre. We must all converge towards an ontological approach of problem stating and problem solving. Indeed, before solving a problem, it must be stated well! This is the art of abduction (i.e., knowing how to imagine assumptions and goals, look for opportunities and ultimately seek meaning) [Boy, 2012].

\section{Intelligent User Interfaces}

Intelligent User Interface (IUI) design and evaluation is a vast and rich research and development area, which is at the intersection of human-system interaction and artificial intelligence, but also of cognitive sciences. Research on such user interfaces appeared in the early 80s (see for instance [Edmonds, 1981]); in fact the first concepts date from late 70s in terms of so-called adaptive approaches. Many definitions have been proposed in the literature. So [Hancock and Chignell, 1989] defined them as interfaces which provides tools to help minimise the cognitive distance between the mental model which the user has of the task, and the way in which the task is presented to the user by the computer when the task is performed. It even seems possible to go beyond this definition because, starting from the model of the theory of action of [Norman, 1986], while lying in an adaptive approach (many others were studied in literature, see below), it is possible to locate different cognitive stages, against which one or more adaptations are especially important, Figure 1.

Among the many other definitions include that of [Maybury, 1999]: "Intelligent User Interfaces (IUI) are human-machine interfaces that aim to improve the efficiency, effectiveness, and naturalness of human-computer interaction by representing, reasoning, and acting on models of the user, domain, task, discourse, and media (e.g., graphics, natural language, gesture). IUI are multifaceted, in purpose and nature, and include capabilities for multimedia input analysis, multimedia presen- 


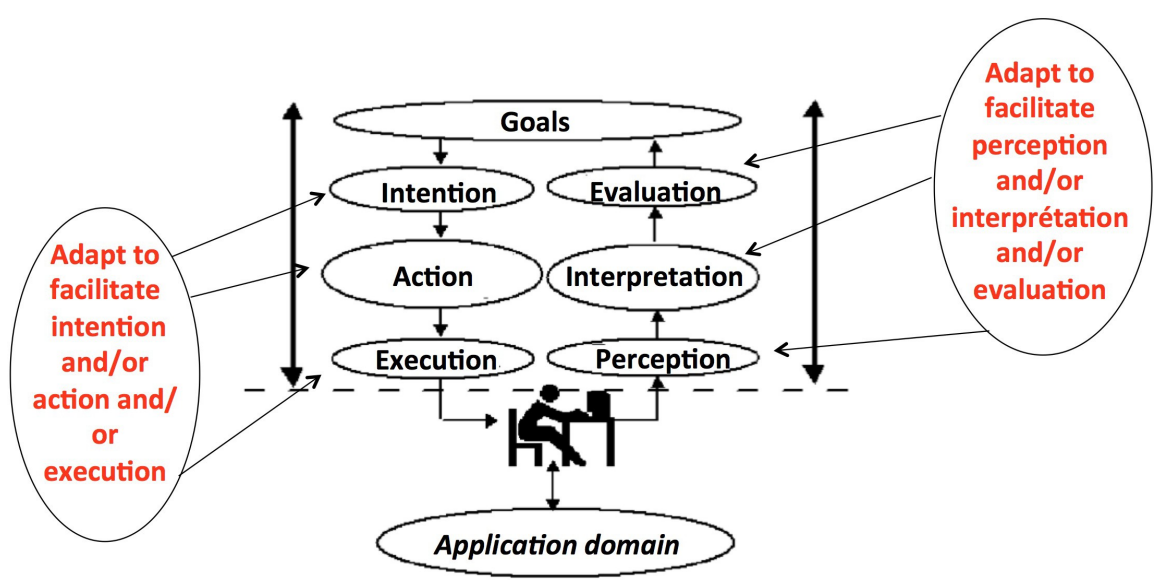

Fig. 1 Adaptation(s) in the light of the Norman's Theory of Action (adapted from [Norman, 1986])

tation generation, model-based interfaces, agent-based interfaces, and the use of user, discourse and task models to personalize and enhance interaction. [. . .]".

Consequently, the field of intelligent interfaces covers a disciplinary field representing the intersection of human-system interaction, software ergonomics, cognitive science and artificial intelligence, including their respective sub-disciplines such as computer vision, automatic language processing, knowledge representation and reasoning, machine learning, knowledge discovery, planning, modeling of software and human agents, modeling of speech. It is also commonly accepted that the field of intelligent interfaces represents the intersection of human-system interaction and artificial intelligence, as well as Engineering of Interactive Computing Systems (EICS) represents the intersection of the human-system interaction and software engineering.

The definition of Maybury is interesting because it highlights that such user interfaces are designed to provide solutions in relation to different underlying criteria for human-system interaction, and they need to take into account explicitly several models to cover a set of steps in relation to Perception, Cognition and Action (if one refers to the PCA model well known in Artificial Intelligence). Included are problems and recurring locks associated with the recognition of user (or user group) intention, modeling knowledge and preferences, communication with the user, and also the reasoning and the decision making (what, when, where, to whom, how, why to present the information).

Intelligent user interfaces are now a field in its own right. It is important to emphasise that famous conference of the Association of Computing Machinery (ACM) is dedicated to them. This is called ACM IUI (Intelligent User Interfaces). From a historical perspective (see also http://www.iuiconf.org/IUI/History), the idea started with a workshop in March 1988 entitled "Architectures for Intel- 
ligent Interfaces", resulting in 1991 in the book "Intelligent User Interfaces" published by J.W. Sullivan and S.W. Tyler, workshop organisers). After a first workshop sponsored by the ACM in 1993, IUI has become an annual conference in 1997. In the call of the 2017 edition, note that the topic highlighted were the following: Intelligent visualisation tools, User-Adaptive interaction and personalisation, Recommender systems, Intelligent wearable, mobile and ubiquitous interfaces, Modeling and prediction of user behaviour, Information retrieval and search, Education and learning-related technologies, Social media analysis, Multi-modal interfaces (speech, gestures, eye gaze, face, physiological information etc.), Natural language and speech processing, Generation of multimodal content, Big Data and analytics, Smart environments and tangible computing, Intelligent assistants for complex tasks, Collaborative interfaces, Persuasive and assistive technologies in IUI, Affective and aesthetic interfaces, Interactive machine learning, Planning and plan recognition for IUI, Knowledge-based approaches to user interface design and generation, Proactive and agent-based user interaction, Example-and demonstration-based interfaces, Evaluations of intelligent user interfaces. In addition to the regular publication of many books and articles on intelligent user interfaces in various journals and conferences, both in human-system interaction and in Artificial Intelligence, we can point out that both journals are dedicated to them: User Modeling and User-Adapted Interaction (Springer) ; ACM Transactions on Interactive Intelligent Systems.

Many approaches contributing to intelligent user interfaces can be found in the literature. It is not possible to mention them all here; the interested reader can find in various books or review papers further details on this topic [Chignell and Hancock, 1988; Kolski and Le Strugeon, 1998; Hook, 2000; Jameson, 2007; Akiki et al, 2014]:

- The so-called adaptive approaches are those that led to most proposals (cf. [Kolski et al, 1992; Schneider-Hufschmidt et al, 1993; Jameson and Gajos, 2012]), the adaptation being usually relatively different user and/or task characteristics or task.

- In continuation of work on adaptation, there are approaches on the current trend of providing more personalised services to users of information systems at large. It is in this case to adapt to the goals (needs or reasons that led the user to query the system), habits/preferences (all the criteria that distinguish a solution of another for the same query), the user capabilities (including both hardware and software capabilities available to the user, as its own physical or cognitive abilities, possibly related to disabilities). It is important that the system learns during the interaction with the user, as well as with users with close profile, to further customise, exploiting for example collaborative filtering algorithms [Su and Khoshgoftaar, 2009]. The works are numerous in this area [Abed et al, 2011; Brusilovsky et al, 2007; Peintner et al, 2008; Findlater and Gajos, 2009; de Oliveira et al, 2013; Germanakos and Belk, 2016].

- Certain intelligent user interfaces are called tolerant to human error [Rouse and Morris, 1987; Beka Be Nguema et al, 2000]. In this case the adaptation operates a classification of possible human errors and their consequences. Their goal of such IUI is to correct human error or alert the user in case of potential problems. 
- Another category includes assistants, in the broadest sense of the term. They are at the service of the users, listening to them, to assist them in case of problems [Lieberman, 1995]. A typical example is the assistant, called Clippy, integrated in several previous versions of the Microsoft Office environment. This assistant was made available to the user and advising (requested or not) on appropriate procedures (like how repaginate a document). Such approach was originally proposed in the aviation field, under the name of intelligent operator assistant, acting as co-pilot in a cockpit and reasoning in parallel to the user considered as the final decision maker [Boy, 1991a]. To improve the human-system interaction, to make it more natural, the design choices may include a human physiognomy of the assistant, see about the "Affective Embodied Conversational Agents" section of this chapter.

- Many researches focus on context in general and how to take it into account in UI design. The definitions of [Abowd et al, 1999] and [Dey, 2001] on this subject are the most cited. Different types of context-aware systems are also studied. It is in fact possible to find in the literature the following qualifiers: Context-aware and Context-sensitive, which denote the fact of using the context or the one to adapt to it. The works are numerous in this area [Boy, 1991b, 1992; Winograd, 2001; Coutaz and Rey, 2002; Limbourg et al, 2004; van den Bergh, 2006; Brossard et al, 2011; Bauer et al, 2014; Bauer and Dey, 2016].

- The objective of the so-called plastic user interfaces is to adapt to their context of use in respect of their usability [Thevenin and Coutaz, 1999]. The context of use must consider the characteristics of the user, platform of interaction, and environment [Calvary et al, 2004; Sottet et al, 2009; Coutaz and Calvary, 2012].

- A more prospective approach considers the intelligent user interface and its socio-technical environment as a multi-agent system. It corresponds to a distributed approach to human-system interaction. It is important to note that, more generally, distributed user interfaces are subject of much research currently [Gallud et al, 2011; Lozano et al, 2013; Gallud et al, 2014]. Such an interface, suggested by [Mandiau et al, 1991; Kolski and Le Strugeon, 1998], is composed of cognitive and reactive agents, working in parallel and/or cooperating in order to solve different problems relating to the tasks. The result of their treatment is provided to users through acts of communication, but we can imagine a variety of other actions directly on the system, for example. This principle was implmented as part of a road traffic simulation on interactive tabletop with RFID technology, virtual agents representing vehicles responding to the activation of tangible objects manipulated by users [Kubicki et al, 2013; Lebrun et al, 2015].

The areas of application of intelligent user interfaces are multiple, since they can be a contribution when a semi-automatic or automatic aid should be implemented by the interactive system, while taking into account different criteria or user preferences. Research and development focused as well on tasks considered as relatively simple (office, information retrieval, e-commerce, etc.) than on complex tasks, even critical (transport, supervision, health). 


\section{Affective Embodied Conversational Agents}

Computers are increasingly used in roles that are typically fulfilled by humans, such as virtual tutors in a learning class or virtual assistants for task realisation. When computers are used in these roles they are often embodied by animated cartoon or human like virtual characters, called Embodied Conversational Agents (ECA) [Cassell, 2000]. An example of an ECA is illustrated Figure 2. This enables a more natural style of communication for the human and allows the computer to avail of both verbal and non-verbal behaviour channels of communication. Several studies have demonstrated the acceptance and the efficiency of such agents [Krämer, 2008]; indeed, the persona effect reveals that the presence of an ECA improves the subjective experience of an interaction for the user. Moreover, when people interact with such virtual agents, they tend to react naturally and socially as they would do with another person [Krämer, 2008].

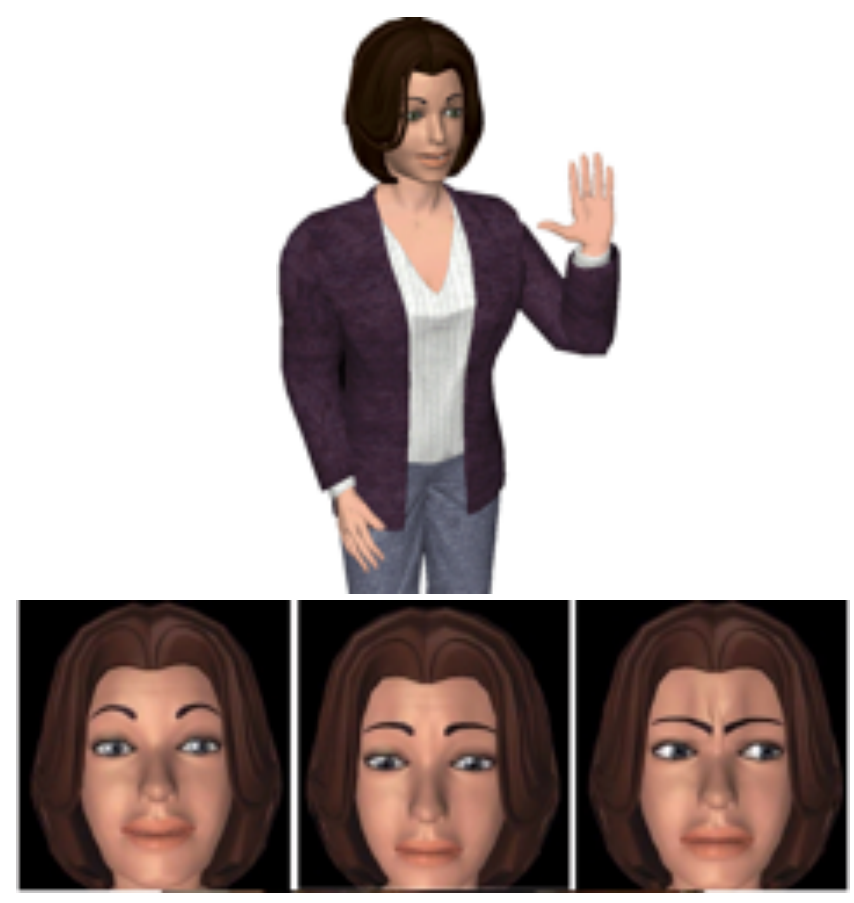

Fig. 2 Example of an Embodied Conversational Agent: the ECA Greta [Pelachaud, 2009]. Expressions of joy, sadness, and anger (from left to right).

The ECAs are not only simple humanoid graphical representations but embody (1) cognitive agents able to reason on complex internal semantic representation, (2) interactive agents able to interact in a multimodal way with a user, and (3) expressive agents able to show, through their verbal and non-verbal behavior, a particular 
cognitive and affective mental state. These three dimensions - cognitive, interactive and expressive - are essential to design an ECA to improve the interaction both concerning the satisfaction of the user and concerning the user's performance in task achievement. For instance, several research has shown that agents expressing emotions improve the interaction [Beale and Creed, 2009]. However, the expressive capacity of the agent is not sufficient : an emotion expressed in an inappropriate situation during an interaction may have a negative impact on the user's perception [Ochs et al, 2012b]. That is the three dimensions - cognitive, interactive and expressive - that enable the agent to adopt an affective behavior relevant and efficient during the interaction with the user.

The cognitive dimension of an ECA means a representation of knowledge and a capacity to reason on them ${ }^{4}$. The knowledge refers to information related to the application domain and the task ; but also to the knowledge related to the social and emotional dimension of the interaction. Indeed, an ECA has to be able to represent and reason on its own emotions and those of its interlocutor given the social context. The cognitive representation of emotions has to include a representation of the conditions of elicitation of emotions, i.e. when an individual may feel which emotion(s) given a situation. This information may be used by the ECA to identify when the ECA itself may express which emotion(s) but also which emotion(s) the user may potentially feel during the interaction. The elicitation of emotion being tightly related to the achievement or failure of a goal [Scherer, 2000], the BDI representation (Belief, Desire and Intention) of emotions - through syntactic abbreviations of combinations of mental attitudes - is particularly adapted to this problematic ${ }^{5}$. Such a formalization has for instance been used to develop en ECA that is capable to express empathy toward the user during a dialogue [Ochs et al, 2012b] or a virtual tutor that adapts its pedagogical strategy to the inferred emotions of the user [Jaques and Viccari, 2004]. Others methods have been proposed to represent emotions. For instance, to illustrate the dynamical aspect and the non-determinism of emotions, a representation based on Bayesian network [de Melo et al, 2012] and Dynamic Belief Network [deRosis et al, 2003] have been developed.

Moreover, the emotions of an agent may be used to determine the appropriate behavior of the agent in a virtual environment. The emotions are then integrated in the decision making process for the actions selection [Canamero, 2003]. Inspired by the coping theory claiming that people used specific cognitive strategy to cope with their emotions [Lazarus, 1991], the impact of emotions on an ECA's behavior may be modeled by a modification of its mental state, i.e. a modification of its beliefs, desires and intentions [Gratch and Marsella, 2004]. For instance, if the ECA has a negative emotion, it can adopt an acceptation strategy implying the fact that the agent gives up the intention that has elicited the negative emotion by its failure. By consequence, the negative emotion of the agent will disappear.

\footnotetext{
${ }^{4}$ The reader can refer to the volume 1 of this book for an overview of the methods in Artificial Intelligence for the representation of knowledge and the reasoning

${ }^{5}$ An example of a BDI formalisation of emotions is proposed in Chapter 1.16 volume 1 of this book.
} 
In interaction with the user, the emotional knowledge of the agent should be enriched given the progress of the interaction. Indeed, even if a formalisation of emotions may enable the agent to infer the user's emotions, a system to recognise in real-time the emotions expressed by the user may validate, refute or refine the agent's emotional knowledge, in particular concerning the effects of agent's actions on user's emotions. During the interaction, the user expresses her/his emotions through her/his non-verbal behavior (e.g. facial expressions and voice), her/his verbal behavior (e.g. emotional words) and through physiological signals (e.g. skin conductance). The system to automatically recognised emotions are generally constructed on an offline learning of the non-verbal, verbal or physiological characteristics of emotions based on real or acted corpus of data of individual feeling or expressing emotions.

For instance, audio-visual corpora are collected to analyse the facial, gestural and acoustic characteristics of emotions expressed by individuals. The corpora of emotion expressions are generally manually annotated with different types of emotion and sometimes with associated intensity values. A method to extract emotional knowledge from these corpora consists in exploiting machine learning methods ${ }^{6}$, and more precisely supervised algorithms to correlate expressive characteristics (such as muscles activation of the face or acoustic parameters of the voice) to emotion types and intensity [Caplier, 2011; Clavel and Richard, 2011].

The machine learning methods are also used for the generation of the expressive behaviors of ECAs (head movements, gaze direction, posture, etc.). The analysis of interpersonal interactions in corpora can be exploited to identify how an affective or cognitive state is expressed through facial expressions gestures or postures; but also how individuals coordinate their non-verbal behavior (e.g. mimicry). In this learning problematic of ECA's non-verbal behavior, two approaches may be distinguished. Algorithms said "black box"7 can be used to model ECA's non-verbal behavior that is reflex or slightly correlated to another modality. For instance, an Hidden Markov Model is learn to predict the head movements of an ECA during an interaction with a user or for the its lips synchronisation with its speech [Hofer and Richmond, 2010]. In contrary, algorithms said "white box" are used to extract knowledge that then are explicitly represented in the ECA. For instance, a classification method based on decision tree is used to identify the morphological and dynamic characteristics of different types of smile for ECA (amused, polite and embarrassed smiles) [Ochs et al, 2012a]. To convey the variability of emotion expressions, models integrating the uncertainty to activate some muscles of the face or some gestures based on fuzzy logic rules (as for instance in [Niewiadomski and Pelachaud, 2007]) has been proposed.

Finally, the conception of ECAs implies different problematic inherent to Artificial Intelligence : knowledge representation, decision making, planning and learning. These problematic, applied to model this complex phenomena of emotions, aim

\footnotetext{
${ }^{6}$ Machine learning methods are presented in details in Chapter 1.9, volume 1 of this book.

${ }^{7}$ the results of such algorithms are difficult to explain and to interpret, for instance System Vector Machine (SVM) or Neural Networks.
} 
at integrating in interactive systems an emotional intelligence [Salovey et al, 2000], essential for an optimised human-machine interaction.

\section{Consolidating, formalising and exploiting usability knowledge for designing and evaluating interactive systems}

Designing and evaluating interactive systems have been very active domains of research since more than three decades primarily for one reason: to formalise usability knowledge so as to integrate it into a computational framework which would then be able to express this knowledge at a high level of abstraction, to assess it, to test it, and to fix any potential usability problem detected. The goal is to be released from the empirical assessment traditionally induced by various approaches using this usability knowledge. For instance, [Ivory and Hearst, 2001] observed that different software for evaluating accessibility guidelines on the same web site may produce inconsistent results. Several reasons may explain this: accessibility guidelines are not formalised, if they are, the formalisation is varying depending on the interpretation used by different methods. [Jambon et al, 2001] listed and classified several dozens of methods and techniques for specifying an interactive system that largely vary depending on their perspective: psycho-ergonomic, Engineering of Interactive Computing Systems (EICS), software engineering. [Vanderdonckt and Coyette, 2007], as well as [Beaudouin-Lafon and Mackay, 2003] also reported on several techniques and software for prototyping user interfaces in order to assess them as early as possible. Since the eighties, research and development mainly focused on model-based methods for designing user interfaces: the designer creates one or many models (e.g., a domain model, a task model, a user model, etc.) which are subsequently used for semi-automatic generation of user interface code and/or evaluating it. If this generation is not made possible, at least a structured development life cycle is induced by the models. Literature is significant in this area: [Szekely, 1996; Vanderdonckt and Puerta, 1999; Paterno, 1999; Kolski and Vanderdonckt, 2002], ... Later on, research and development progressively shifted its focus of attention to structured methods based on Model-Driven Engineering (MDE) in line with the initiative launched by the Object Management Group (www.omg.org). Most approaches adopt a top-down life cycle in which models are progressively transformed until the code of a final user interface is obtained. The Cameleon Reference Framework (CRF) [Calvary et al, 2003] now reached a consensus in the community that four levels of abstraction could structure this development life cycle: task and domain, abstract user interface, concrete user interface, and final user interface. This framework is now recommended by the W3C Group on Model-Based User Interface (MBUI) [Gonzlez Calleros et al, 2010], https://www.w3.org/TR/mbui-intro/. Several works are compliant with this $\mathrm{W} 3 \mathrm{C}$ recommendation, such as, but not limited to: [Jacob et al, 2004; Calvary et al, 2008; Seffah et al, 2009; Hussmann et al, 2011], etc. Regarding evaluation of interactive systems, especially with respect to usability and accessibility [Nielsen, 1993; Bastien and Scapin, 2001], but also with respect 
to acceptability [Stephanidis, 2009], many methods, techniques, and software also exist that offer ample possibilities depending on the availability of the user interface (vs a prototype of it) and real users (vs a representation of these users). For instance, when real users are not available, a model of these users is used instead. Further reading can be found in [Nielsen, 1993; Baccino et al, 2005; Huart et al, 2008; Ezzedine et al, 2012; Jacko, 2012]. A problem subsumed by designing and evaluating interactive systems consists in how to create and manipulate the knowledge bases containing the usability knowledge required for the knowledge-based approaches for design and evaluation. [Vanderdonckt, 1999] discusses five major milestones required to create a usability knowledge-based software: guidelines collecting, guidelines organisation, guidelines incorporation into approach, guidelines operationalisation, and guidelines usage. Probably the most critical milestone is the operationalisation since a guidelines as initially stated in a source could be significantly reduced or constrained when incorporated in a knowledge-based approach.

Any guideline could be related to important ergonomic criteria [Bastien and Scapin, 1993] for guidance, dialogue control, error management, consistency, workload, adaptability, compatibility, and code significance.

Usability and accessibility guidelines are considered to be a valuable source for supporting the (semi-)automated detection of potential usability/accessibility problems for designing as well as for evaluating [Tran, 2009; Grammenos et al, 2000]. A usability guideline [Vanderdonckt, 1994] is hereby referred to as any design and/or evaluation principle that could be used to produce and/or guarantee the usability quality of a final user interface. Five categories of usability guidelines could be distinguished: design standards, usability principles, usability guides, style guides, and algorithms for knowledge-based generation of user interfaces. For instance, a guideline could be expressed depending on a particular domain of application [Scapin, 1986; Smith and Mosier, 1986] or independently, as in standards. A guideline could be specifically made applicable for a style guide that is related to an operating system. Many standards contains a significant section of guidelines [Stewart and Travis, 2002], such as international norms (e.g., ISO 9241, ISO/IEC 9126), national ones (e.g., HFES, AFNOR, BSI . . . ). Figure 3 sorts these five types of guidelines according to their level of applicability: standards are considered as the most general sources of usability knowledge, therefore widely applicable in principle, but also requiring some interpretation to be correctly applied depending on the context of use and all its dimensions (user, platform, and environment). On the other side of this continuum, design rules only require a minimal interpretation before applying them since their applicability is specific. The more general a guideline is, the more interpretation it may require in order to properly apply it.

Figure 4 locates guidelines depending on two axes: the need for interpretation and the level of precision required to implement them in a software. Algorithms are straightforward to be applied since they require almost no interpretation, but are totally driven by their specifications, which make them notably inflexible. On the other side, principles require a high level of interpretation, thus making them cautious to apply. A particular condition imposed by a context of use may validate or invalidate the application of such principles. 


$\left.\right|_{\frac{\text { Compilations of guidelines }}{\text { Style guides }}} ^{\text {Ergonomic algorithms }}$

Fig. 3 Five types of guidelines sorted by level of applicability.

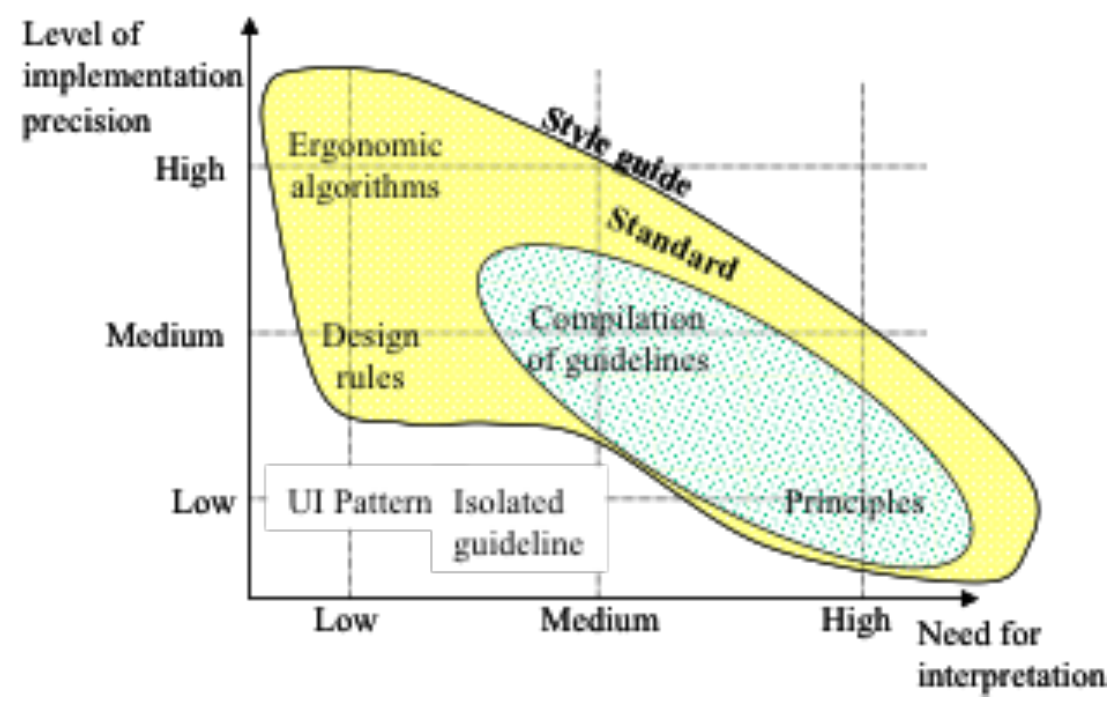

Fig. 4 Guidelines sorted by their level of interpretation and their implementation precision.

Several research and development problems related to intelligent user interfaces, which is often considered as the overlapping of human-computer interaction and artificial intelligence, are still open, such as:

- Consolidation of knowledge-based approaches for user interface design and evaluation: there is a lack of systematic method, a lack of consensus in which approach could be considered valuable, and a lack of properly integrating techniques from knowledge engineering (see chapter I.20).

- Uncertainty of usability knowledge: many guidelines used in knowledge-based approaches are intrinsically uncertain: they are fuzzy, incomplete, redundant, 
hard to access and to modify by a non-expert person, and their notable independence with respect to the context of use unless such a context model is used [Vanderdonckt, 1999].

- Lack of knowledge evolution: knowledge contained in knowledge bases used for user interface design, generation, evaluation is often constant and hard to modify, which may not satisfy the need for making it evolving depending the context of use, but also depending on the dynamic evolution of users. Machine learning techniques are particularly welcome for this purpose, which explain why knowledge could be improved by actual data of its usage.

\section{Visualisation and data mining}

Data processing and mining are nowadays a priority both in research and industry, small or large. Organisations now produce loads of data on their internal processes as well as on their client activities. Technological or strategic watch requires to collect and forage all available data in order to gain a competitive edge over competing organisations, or to better position themselves in the socio-economical context [Provost and Fawcett, 2013].

Data can be massive - as in "big". Data is also complex, just as the phenomenon they emerge from, but also because it often is non-structured. Seeking for the information encapsulated within the data is difficult, discovering new insights from data is challenging [Zhang et al, 2012].

Data mining develops algorithms capable of identifying structural patterns, expressed as association rules for instance. A classical example is that of a supermarket seeking a better understanding of consumers' habits, typically through the use of fidelity cards or mobile application account, in order to refine its marketing strategy. A telecom company will foresee the possibility to better understand how the teenager market differs from adult consumers. Data mining results can be complex just as the data that needs to be processed; they often need to be sorted, organised or classified before decision can be made.

Data mining is all about discovering structural patterns. Information visualisation relies on a crucial observation, that around $40 \%$ of our cortex activity is devoted to processing visual signals [Ware, 2000]. The challenge is thus to propose users with a graphical representation from which patterns in data now turned into visual patterns can be inferred. Being able to interactively manipulate and query the map additionally allows users to gain insight on the visual display of information. The literature gathers tons of approaches to graphically display data on the screen, often targeting specific types of data: temporal data [Silva and Catarci, 2000] [Daassi et al, 2006], geospatial data [Andrienko and Andrienko, 2006], networksseaux [Herman et al, 2000] [Landesberger et al, 2011] or multi-dimensional dataes multi-dimensionnelles [Hoffman and Grinstein, 2002].

Visualisation aims at solving a problem which, although it can easily be formulated, can turn out to be quite complex. Computing cartesian coordinates of data 
points is but the first step. Visualisation also requires to use relevant visual variables (color, shapes, saliences, etc.) to highlight attribute properties (statistical distribution, correlation, proximity distorsion, etc.). Computing screen positions most of the times is a combinatorial optimisation problem while visual encodings involve graphics semiotics [Bertin, 1998] [Ware, 2000] and escape purely computational approaches.

Visualisation is part of data and information processing. This process traditionally is represented as a pipeline chaining data processing steps, starting from data curation and organisation, statistical/combinatorial analysis up to computing a representation in (usually 2D) Euclidean space and its rendering on a screen [Card et al, 1999] [Chi, 2000] [dos Santos and Brodlie, 2004]. This process, although depicted as a pipeline, does not necessarily deploys itself in sequence, but rather as iterations allowing structure to emerge and hypothesis to be formed: early iterations help focus on relevant subsets of data that need further investigation, leading to hypothesis that can be tested; visualisation will additionally be useful to disseminate results and support decision making. This process echoes Shneiderman's mantra ("Overview first, zoom and filter, then details on demand" [Shneiderman, 1996]) and has been termed the "Sense-making loop" (cf. Figure 5) by the Visual Analytics founders Thomas and Cook [Thomas and Cook, 2006].

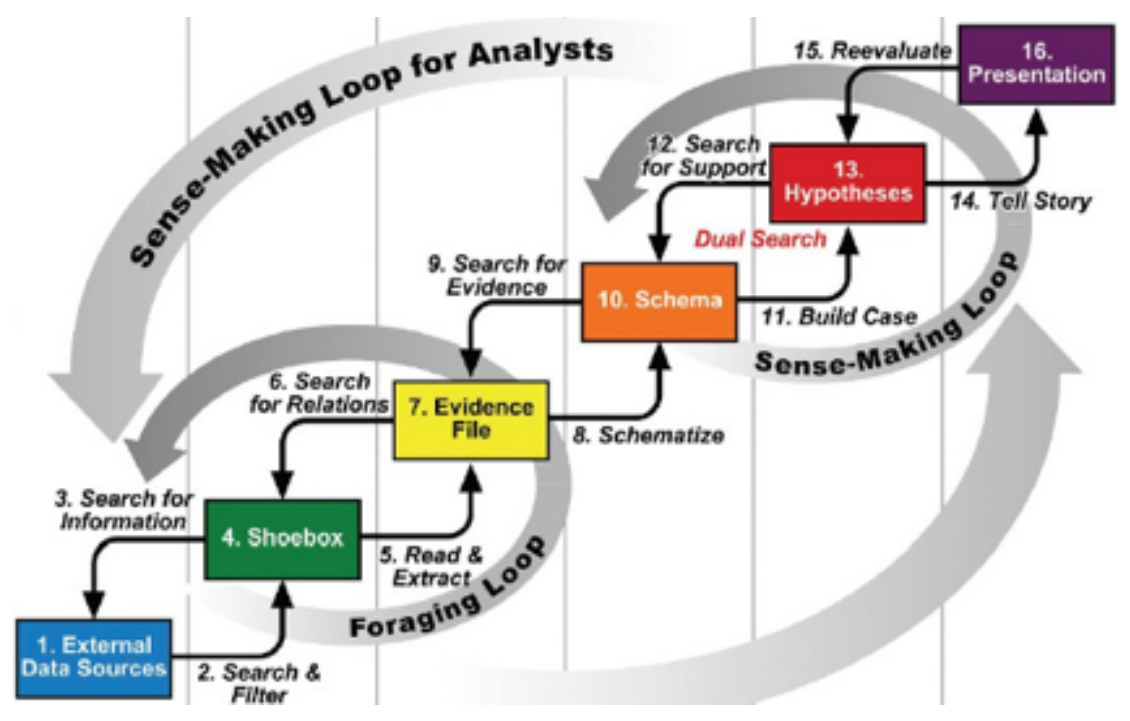

Fig. 5 The "Sense-Making Loop" illustrates the iterative process relying on visualisation as a main driver of the analytical process [Thomas and Cook, 2006].

Because the data is complex, uncertain and changing, human intelligence resides at the heart of the foraging process. Echoing Shneiderman's mantra, Visual Analytics promoted by Thomas \& Cook has established as a research area since a few 
decades. More than data analysis or pattern recognition, Visual Analytics aims at knowledge discovery.

The visualisation pipeline and the Sense-Making loop places users at the centre of the knowledge discovery process [van Wijk, 2005]. While the pipeline maps to a high level data processing architecture, it is human computer interaction that enables users to drive data foraging. As a consequence, identifying why and how a given visualisation technique is more "efficient" in supporting human driven knowledge discovery is crucial. Controlled user experiments, often exercised in the area of human compter interaction studies, has now become common practice to validate visualization techniques [Purchase, 2012] [Sedlmair et al, 2012] [Isenberg et al, 2013].

These controlled experiments indeed can help compare techniques supporting low-level, fine grained tasks [Amar et al, 2005] [Lee et al, 2006]. Knowledge discovery however is a high high-level cognitive process. Controlled experiments can hardly validate that a technique (or more often a combination of techniques) favors knowledge discovery. Evaluation high-level cognitive processes does not boil down to error rates and time to task completion. They are more conveniently described in terms of design principles and best practice. Munzner [Munzner, 2009] (see also [Meyer et al, 2012], [Brehmer and Munzner, 2013]) proposes a nested model for the design of visualisation systems where data abstractions and user interactions are derived from domain questions. User tasks derived from these questions then specify requirements on visual encodings, including interaction, relevant visual representations and visual variables. Validating of a visualisation then unfolds in the opposite direction: algorithms must run under proper time complexity to insure fluidity of user action and are measured either theoretically or tested against benchmark datasets. Controlled experiments may be used to assess the efficiency of combined visual encodings and interaction techniques. User interviews can assess usability of the overall system (as an aid to decision making, for instance). User adoption of the system is the ultimate demonstration of the value of a visualisation technique [van Wijk, 2005].

Visualisation can thus reveal structures hidden in data that is uncovered by analysis and mining approaches. It becomes a natural companion to artificial intelligence precisely because it engages human cognitive capabilities and intelligence. And because it addresses complex phenomenon emerging from real world situations, often explored and examined in an uncertain and changing environment.

\section{Conclusion}

In this chapter, we wanted to give an overview of cross-fertilisation between HCI and AI focused on several key representative research areas without exhaustibity constraints. Significant work at the intersection of these two fields started forty years ago in the aeronautical field, closely combining intelligence and interactivity. This work is now continuing in different areas (simulation, semantic web, e-commerce, 
social networks, complex dynamic systems, ambient intelligence, and so on). Smart user interfaces quickly took advantage of the complementarity of HCI and AI to become a multifaceted domain. Approaches to user interfaces and affective embodied conversational agents, put forward in this chapter, have particularly promising prospects. Capitalization, formalization and operation of ergonomic knowledge for the design and evaluation of interactive systems have been the subject of many studies since the early 1980s. This will continue for more, since the potential of crossfertilization between $\mathrm{HCI}$ and $\mathrm{AI}$ continues to be a huge endeavor.

Finally, visualization and data mining, whose close ties have been reviewed in the last section of this chapter, are also particularly representative of areas where $\mathrm{HCI}$ and AI join naturally.

\section{References}

Abed M, Anli A, Kolski C, Grislin-Le Strugeon E (2011) A generic method for personalizing interactive systems: application to traveler information. In: Kolski C (ed) Human-Computer Interactions in Transport, ISTE Ltd and John Wiley \& Sons Inc., pp 51-91

Abowd GD, Dey AK, Brown PJ, Davies N, Smith M, Steggles P (1999) Towards a better understanding of context and context-awareness. In: Proceedings of the 1st international symposium on Handheld and Ubiquitous Computing, HUC '99, pp 304-307

Akiki PA, Bandara AK, Yu Y (2014) Adaptive model-driven user interface development systems. ACM Comput Surv 47(1):9:1-9:33, DOI 10.1145/2597999, URL http://doi.acm.org/10.1145/2597999

Amar R, Eagan J, Stasko J (2005) Low-level components of analytic activity in information visualization. In: IEEE Symposium on information Visualization, IEEE Computer Society, pp 111-117

Andrienko N, Andrienko G (2006) Exploratory Analysis of Spatial and Temporal Data - A Systematic Approach. Springer

Asimov I (2008) I Robot. Random House Publishing Group

Baccino T, Bellino C, Colombi T (2005) Mesure de l'utilisabilite' des interfaces. TIC et Sciences Cognitive, Hermes

Bastien JMC, Scapin DL (1993) Ergonomic criteria for the evaluation of humancomputer interfaces. Tech. Rep. 156, INRIA, Rocquencourt

Bastien JMC, Scapin DL (2001) Evaluation des systèmes d'information et critères ergonomiques. In: Kolski C (ed) Environnement évolués et évaluation de l'IHM, Interaction Homme-Machine pour les SI, vol 2, Paris : Hermes, pp 53-80

Bauer C, Dey AK (2016) Considering context in the design of intelli-gent systems: Current practices and suggestions for improvement. Journal of Systems and Software 112:26-47, DOI 10.1016/j.jss.2015.10.041, URL http://dx.doi.org/10.1016/j.jss.2015.10.041 
Bauer JS, Newman MW, Kientz JA (2014) What designers talk about when they talk about context. Human-Computer Interaction 29(5-6):420-450, DOI 10.1080/07370024.2014.896709, URL http://dx.doi.org/10.1080/07370024.2014.896709

Beale R, Creed C (2009) Affective interaction: How emotional agents affect users. International Journal of Human-Computer Studies 67(9):755-776

Beaudouin-Lafon M, Mackay W (2003) Prototyping tools and techniques. In: Jacko JA, Sears A (eds) The Human Computer Handbook: Fundamentals, Evolving Technologies, and Emerging Applications, L. Erlbaum Associates Inc., Hillsdale, NJ, USA, pp 1006-1031

Beka Be Nguema M, Kolski C, Malvache N, Waroux D (2000) Design of a humanerror-tolerant interface using fuzzy logic. Engineering Applications of Artificial Intelligence 13(3):279-292

Bellot P (2011) Recherche d'information contextuelle, assistée et personnalisée. Collection recherche d'information et web, Lavoisier, Paris.

van den Bergh J (2006) High-level user interface models for model-driven design of context-sensitive user interfaces. $\mathrm{PhD}$ thesis, Hasselt University, Belgium

Berners-Lee T, Hendler J, Lassila O (2001) The semantic web. Scientific American Magazine

Bertin J (1998) Sémiologie Graphique : Les Diagrammes, Les Réseaux, Les Cartes. Les ré-impressions, Ecole des Hautes Etudes en Sciences Sociales

Boy G (1991a) Intelligent assistant systems. Academic Press, New York

Boy GA (1991b) Indexing hypertext documents in context. In: Proceedings of Hypertext '91, ACM Press, pp 51-61

Boy GA (1992) Semantic correlation in context: Application in document comparison and group knowledge design. In: AAAI Spring Symposium on Cognitive Aspects of Knowledge Acquisition

Boy GA (1998) Cognitive Function Analysis. Ablex/Greenwood, Westport, USA

Boy GA (2012) Orchestrating Human-Centered Design. Springer, U.K.

Brehmer M, Munzner T (2013) A multi-level typology of abstract visualization tasks. IEEE Trans. on Visualization and Computer Graphics 19(12):2376-2385

Brossard A, Abed M, Kolski C (2011) Taking context into account in conceptual models using a model driven engineering approach. Information and Software Technology 53(12):1349-1369

Brusilovsky P, Kobsa A, Nejdl W (eds) (2007) The Adaptive Web: Methods and Strategies of Web Personalization. Springer Verlag, Heidelberg, Germany

Calvary G, Coutaz J, Thevenin D, Limbourg Q, Bouillon L, Vanderdonckt J (2003) A unifying reference framework for multi-target user interfaces. Interacting with Computers 15(3):289-308

Calvary G, Coutaz J, Dâassi O, Balme L, Demeure A (2004) Towards a new generation of widgets for supporting software plasticity: The "comet". In: Engineering Human Computer Interaction and Interactive Systems, Joint 
Working Conferences EHCI-DSVIS 2004, Hamburg, Germany, July 11-13, 2004, Revised Selected Papers, pp 306-324, DOI 10.1007/11431879_21, URL http://dx.doi.org/10.1007/11431879_21

Calvary G, Pribeanu C, Santucci G, Vanderdonckt J (eds) (2008) Computer-Aided Design of User Interfaces $\mathrm{V}$ - Sixth International Conference of Computer-Aided Design of User Interfaces 2006, Springer, Bucharest, Romania

Canamero L (2003) Designing emotions for activity selection in autonomous agents. In: Trappl R, Petta P, Payr S (eds) Emotions in Humans and Artifacts, MIT Press: $115-148$

Caplier A (2011) Visual emotion recognition: Status and key issues. In: Pelachaud C (ed) Emotion-oriented systems, John Wisley

Card S, Mackinlay J, Shneiderman B (1999) Readings in Information Visualization. Morgan Kaufmann Publishers, San Francisco

Card SK, Moran TP, Newell A (1983) The Psychology of Human-Computer Interaction. Lawrence Erlbaum Associates, Hillsdale, NJ

Cassell J (2000) More than just another pretty face: Embodied conversational interface agents. Communications of the ACM 43:70-78

Chi EH (2000) A taxonomy of visualization techniques using the data state reference model. In: IEEE Symposium on Information Vizualization, IEEE Computer Society: $69-75$

Chignell MH, Hancock PA (1988) Intelligent interface design. In: Helander M (ed) Handbook of Human-Computer Interaction, Amsterdam: Elsevier, pp 969-995

Clavel C, Richard G (2011) Recognition of acoustic emotion. Emotion-Oriented Systems. In: Pelachaud C (ed) Emotion-oriented systems, John Wisley

Coutaz J, Calvary G (2012) HCI and Software Engineering for User Interface Plasticity, CRC Press, taylor and Francis Group, pp 1195-1220

Coutaz J, Rey G (2002) Foundations for a Theory of Contextors. In: Kolski C, Vanderdonckt J (eds) Computer-Aided Design of User Interfaces III - Fourth International Conference of Computer-Aided Design of User Interfaces, Kluwer Academic, vol 3, pp 13-34

Daassi C, Nigay L, Fauvet MC (2006) A taxonomy of temporal data visualization techniques. Revue Information Interaction Intelligence 5(2):41-63

deRosis F, Pelachaud C, Poggi I, Carofiglio V, Carolis BD (2003) From Greta's mind to her face: Modelling the dynamics of affective states in a conversational embodied agent. Intl. Journal of Human-Computer Studies 59(1-2): 81-118.

Dey AK (2001) Understanding and using context. Personal Ubiquitous Comput 5(1):4-7

Edmonds EA (1981) Adaptive man-computer interfaces. In: Coombs MJ, Alty JL (eds) Computing skills and the user interface, London: Academic, pp 389-426

Ezzedine H, Trabelsi A, Tran C, Kolski C (2012) Critères et méthodes d'évaluation des systèmes interactifs, application un poste de régulation dans le domaine des transports. In: Hammadi S, Ksouri M (eds) Ingénierie du transport et des services de mobilité avancés, Hermes, Paris, pp 213-293 
Findlater L, Gajos KZ (2009) Design space and evaluation challenges of adaptive graphical user interfaces. AI Magazine 30(4):68-73, URL http://www.aaai.org/ojs/index.php/aimagazine/article/view/2268

Ford KM, Glymour C, Hayes PJ (1997) Cognitive prostheses. AI Magazine 18(3)

Gallud JA, Tesoriero R, Penichet VMR (eds) (2011) Distributed User Interfaces Designing Interfaces for the Distributed Ecosystem. Springer

Gallud JA, Lozano MD, Vanderdonckt J (2014) Distributed user interfaces: Usability and collaboration. Int J Hum-Comput Stud 72(1):44, DOI 10.1016/j.ijhcs.2013.10.006, URL http://dx.doi.org/10.1016/j.ijhcs.2013.10.006

Germanakos P, Belk M (2016) Human-Centred Web Adaptation and Personalization - From Theory to Practice. Human-Computer Interaction Series, Springer, DOI 10.1007/978-3-319-28050-9, URL http://dx.doi.org/10.1007/978-3-319-28050-9

Gonzlez Calleros J, Meixner G, Patern F, Pullmann J, Raggett DS, Vanderdonckt J (2010) Model-based ui xg final report. In: Cantera Fonseca J (ed) W3C Incubator Group Report, URL http://www.w3.org/2005/Incubator/model-basedui/XGR-mbui-20100504/

Grammenos D, Akoumianakis D, Stephanidis C (2000) Integrated support for working with guidelines: the sherlock guideline management system. Interacting with Computers 12(3):281-311

Gratch J, Marsella S (2004) A domain-independent framework for modeling emotion. Journal of Cognitive Systems Research 5(4):269-306

Grudin J (1994) Computer-supported cooperative work: History and focus. Computer 27(5):19-26

Hancock PA, Chignell MH (eds) (1989) Intelligent interfaces: theory, research and design. Amsterdam: North-Holland

Herman I, Marshall MS, Melanon G (2000) Graph visualisation and navigation in information visualisation: A survey. IEEE Transactions on Visualization and Computer Graphics 6(1):24-43

Hewett T, Baecker R, Card S, Carey T, Gasen J, Mantei M, Perlman G, Strong G, Verplank W (1992) ACM SIGCHI curricula for human-computer interaction. ACM, New York, NY, USA

Hofer G, Richmond K (2010) Comparison of hmm and tmdn methods for lip synchronisation. In: Kobayashi T, Hirose K, Nakamura S (eds) INTERSPEECH 2010, 11th Annual Conference of the International Speech Communication Association, Makuhari, Chiba, Japan, September 26-30, 2010, ISCA, pp 454-457

Hoffman PE, Grinstein GG (2002) A survey of visualizations for high-dimensional data mining. In: Fayyad U, Grinstein G, Wierse A (eds) Information Visualization in Data Mining and Knowledge Discovery, Morgan Kaufmann Pub., pp 47- 82

Hook K (2000) Steps to take before intelligent user interfaces become real. Interacting with computers 12:409-426

Huart J, Kolski C, Bastien C (2008) L'évaluation de documents multimédias, état de l'art. In: S M (ed) Objectiver l'humain ?, Qualification, quantification, vol 1, Hermes, Paris, pp 211-250 
Hussmann H, Meixner G, Zuehlke D (eds) (2011) Model-Driven Development of Advanced User Interfaces, Studies in Computational Intelligence, vol 340. Springer

Hutchins E (1995) Cognition in the Wild. MIT Press, Cambridge, MA

Isenberg T, Isenberg P, Chen J, Sedlmair M, Möller T (2013) A systematic review on the practice of evaluating visualization. IEEE Transactions on Visualization and Computer Graphics 19(12):2818-2827

Ivory MY, Hearst MA (2001) The state of the art in automating usability evaluation of user interfaces. ACM Computing Surveys 33(4):470-516

Jacko JA (ed) (2012) The Human Computer Handbook: Fundamentals, Evolving Technologies, and Emerging Applications, 3rd edn. CRC Press, Boca Raton, FL Jacob RJK, Limbourg Q, Vanderdonckt J (eds) (2004) Computer-Aided Design of User Interfaces IV - Fifth International Conference of Computer-Aided Design of User Interfaces, Kluwer, Funchal, Portugal

Jambon F, Brun P, Ait-Ameur Y (2001) Spécification des systèmes interactifs. In: Kolski C (ed) Analyse et Conception de l'IHM. Interaction Homme-Machine pour les SI, vol 1, Paris : Editions Hermes, pp 175-206

Jameson A (2007) Adaptive interfaces and agents. In: Sears A, Jacko JA (eds) The Human Computer Handbook: Fundamentals, Evolving Technologies, and Emerging Applications, CRC Press, Boca Raton, FL, pp 433-458

Jameson A, Gajos KZ (2012) Systems that adapt to their users. In: Jacko JA (ed) The Human Computer Handbook: Fundamentals, Evolving Technologies, and Emerging Applications, CRC Press, Boca Raton, FL, pp 431-456

Jaques PA, Viccari RM (2004) A BDI approach to infer student's emotions. In: the Proceedings of the Ibero-American Conference on Artificial Intelligence (IBERAMIA), Springer-Verlag, Puebla, Mexique, pp 901-911

Kolski C, Le Strugeon E (1998) A review of intelligent human-machine interfaces in the light of the arch model. International Journal of Human-Computer Interaction 10(3):193-231

Kolski C, Vanderdonckt J (eds) (2002) Computer-Aided Design of User Interfaces III - Fourth International Conference of Computer-Aided Design of User Interfaces, Kluwer, Valenciennes, France

Kolski C, Tendjaoui M, Millot P (1992) A process method for the design of "intelligent" man-machine interfaces : case study : "the decisional module of imagery". International Journal of Human Factors in Manufacturing 2(2):155-175

Krämer NC (2008) Social effects of virtual assistants. a review of empirical results with regard to communication. In: Proceedings of the international conference on Intelligent Virtual Agents (IVA), Springer, Berlin, Heidelberg, pp 507- 508

Kubicki S, Lebrun Y, Lepreux S, Adam E, Kolski C, Mandiau R (2013) Simulation in contexts involving an interactive table and tangible objects. Simulation Modelling Practice and Theory 31:116-131

Landesberger Tv, Kuijper A, Schreck T, Kohlhammer J, Wijk JJv, Fekete JD, Fellner DW (2011) Visual analysis of large graphs: State-of-the-art and future research challenges. Computer Graphics Forum 30(6):1719-1749 
Lazarus RS (1991) Emotion and adaptation. Oxford University Press

Lebrun Y, Adam E, Mandiau R, Kolski C (2015) A model for managing interactions between tangible and virtual agents on an RFID interactive tabletop: Case study in traffic simulation. J Comput Syst Sci 81(3):585-598, DOI 10.1016/j.jcss.2014.11.011, URL http://dx.doi.org/10.1016/j.jcss.2014.11.011

Lee B, Plaisant C, Parr CS, Fekete J, Henry N (2006) Task taxonomy for graph visualization. In: AVI Workshop on Beyond Time and Errors: Novel Evaluation Methods For information Visualization BELIV '06, ACM, pp 1-5

Lieberman H (1995) Letizia: An agent that assists web browsing. In: Fourteenth International Joint Conference on Artificial Intelligence, IJCAI 95, pp 924-929

Limbourg Q, Vanderdonckt J, Michotte B, Bouillon L, Florins M, Trevisan D (2004) Usixml: A user interface description language for context-sensitive user interfaces. In: ACM AVI'2004 Workshop "Developing User Interfaces with XML: Advances on User Interface Description Languages, pp 55-62

Lozano MD, Mashat AS, Fardoun HM, Gallud JA, Penichet VMR, Tesoriero R, Vanderdonckt J (eds) (2013) Distributed User Interfaces: Models, Methods and Tools, DUI 2013 In conjunction with ACM EICS 2013 Conference, London, UK, June 24th, 2013, URL http://dui.uclm.es/2013/DUI2013Proceedings.pdf

Mandiau R, Kolski C, Millot P, Chaib-Draa B (1991) A new approach for the cooperation between human(s) and assistance system(s): a system based on intentional states. In: Liebowitz J (ed) Expert Systems World Congress Proceedings, Pergamon Press, New-York, vol 3, pp 1672-1679

Maybury MT (1999) Intelligent user interfaces: an introduction (tutorial notes)

de Melo CM, Carnevale P, Read S, Antos D, Gratch J (2012) Bayesian model of the social effects of emotion in decision-making in multiagent systems. In: Proceedings of the 11th International Conference on Autonomous Agents and Multiagent Systems - Volume 1, International Foundation for Autonomous Agents and Multiagent Systems, Richland, SC, AAMAS'12, pp 55-62

Meyer M, Sedlmair M, Munzner T (2012) The four-level nested model revisited: Blocks and guidelines. In: Workshop on BEyond time and errors: novel evaLuation methods for Information Visualization (BELIV)

Munzner T (2009) A nested process model for visualization design and validation. IEEE Transactions on Visualization and Computer Graphics 15:921-928

Nielsen J (1993) Usability Engineering. Academic Press

Niewiadomski R, Pelachaud C (2007) Fuzzy similarity of facial expressions of embodied agents. In: Proceedings of the 7th international conference on Intelligent Virtual Agents, Springer-Verlag, Berlin, Heidelberg, pp 86-98

Norman DA (1986) Cognitive engineering. In: Norman DA, Draper SW (eds) User Centered System Design: New Perspectives on Human-Computer Interaction, Lawrence Erlbaum Associates, Hillsdale, NJ, pp 31-61

Ochs M, Niewiadomski R, Brunet P, Pelachaud C (2012a) Smiling virtual agent in social context. Cognitive Processing 13(2):519-532

Ochs M, Sadek D, Pelachaud C (2012b) A formal model of emotions for an empathic rational dialog agent. Autonomous Agents and Multi-Agent Systems 24(3):410-440 
de Oliveira KM, Bacha F, Houda M, Abed M (2013) Transportation ontology definition and application for the content personalization of user interfaces. Expert Syst Appl 40(8):3145-3159, DOI 10.1016/j.eswa.2012.12.028, URL http://dx.doi.org/10.1016/j.eswa.2012.12.028

Paterno F (1999) Model-Based Design and Evaluation of Interactive Applications, 1st edn. Springer-Verlag, London, UK, UK

Peintner B, Viappiani P, Yorke-Smith N (2008) Preferences in interactive systems: Technical challenges and case studies. AI Magazine 29(4):13-24

Pelachaud C (2009) Modeling Multimodal Expression of Emotion in a Virtual Agent. Philosophical Transactions of the Royal Society B, Biological Science 364:3539-3548

Picard R (1997) Affective Computing. MIT Press

Provost F, Fawcett T (2013) Data science and its relationship to big data and datadriven decision making. Big Data 1(1):51-59

Purchase HC (2012) Experimental Human-Computer Interaction: A Practical Guide with Visual Examples. Cambridge University Press

Rouse WB, Morris NM (1987) Conceptual design of a human error tolerant interface for complex engineering systems. Automatica 23(2):231-235

Salovey P, Bedell B, Detweiler J, Mayer J (2000) Current directions in emotional intelligence research. In: Lewis M, Haviland-Jones J (eds) Handbook of Emotions, Guilford Press, pp 504-520

dos Santos S, Brodlie K (2004) Gaining understanding of multivariate and multidimensional data through visualization. Computers \& Graphics 28(3):311-325 Scapin DL (1986) Guide ergonomique de conception des interfaces hommeordinateur. Tech. Rep. 77, INRIA, Le Chesnay.

Scherer K (2000) Emotion. In: Hewstone M, Stroebe W (eds) Introduction to Social Psychology: A European perspective, Oxford Blackwell Publishers, pp 151-191

Schneider-Hufschmidt M, Khme T, Malinkowski U (eds) (1993) Adaptive User Interfaces. North Holland

Sedlmair M, Meyer M, Munzner T (2012) Design study methodology: Reflections from the trenches and the stacks. IEEE Trans Visualization and Computer Graphics (Proc InfoVis 2012) 18(12):2431-2440

Seffah A, Vanderdonckt J, Desmarais M (eds) (2009) Human-Centered Software Engineering, Software Engineering Models, Patterns and Architectures for HCI, vol 2. Springer, London

Shadbolt N, Hall W, Berners-Lee T (2006) The semantic web revisited. IEEE Intelligent Systems 21(3):96-101

Shneiderman B (1996) The eyes have it: A task by data type taxonomy for information visualization. In: IEEE Conference on Visual Languages (VL'96), IEEE CS Press, pp 336-343

Silva SF, Catarci T (2000) Visualization of linear time-oriented data: a survey. In: Proceedings of the First International Conference on Web Information Systems Engineering., vol 1, pp 310-319

Smith SL, Mosier JN (1986) Guidelines for designing user interface software. Tech. Rep. MTR-10090, ESD-TR-86-278, MITRE Corp., Bedford, MA 
Sottet J, Calvary G, Favre J, Coutaz J (2009) Megamodeling and metamodeldriven engineering for plastic user interfaces: MEGA-UI. In: Human-Centered Software Engineering - Software Engineering Models, Patterns and Architectures for HCI, pp 173-200, DOI 10.1007/978-1-84800-907-3 8, URL http://dx.doi.org/10.1007/978-1-84800-907-3_8

Stephanidis C (2009) The Universal Access Handbook. CRC Press

Stewart T, Travis D (2002) Guidelines, standards, and style guides. In: Jacko JA, Sears A (eds) The Human Computer Handbook: Fundamentals, Evolving Technologies, and Emerging Applications, L. Erlbaum Associates Inc., Hillsdale, NJ, USA, pp 991-1005

Su X, Khoshgoftaar TM (2009) A survey of collaborative filtering techniques. Advances in Artificial Intelligence 19: Article ID 421,425

Szekely P (1996) Retrospective and challenges for model-based interface development. In: Design, Specification and Verification of Interactive Systems 96, Springer-Verlag, pp 1-27

Thevenin D, Coutaz J (1999) Plasticity of user interfaces: Framework and research agenda. In: Sasse A, Johnson C (eds) IFIP TC.13 - HumanComputer Interaction INTERACT99, IOS Press

Thomas JJ, Cook KA (2006) Illuminating the Path: The Research and Development Agenda for Visual Analytics. IEEE Computer Society

Tran CD (2009) Vers un environnement générique et configurable pour l'aide l'évaluation des systèmes interactifs base d'agents, application un système d'aide l'information voyageurs. $\mathrm{PhD}$ thesis, Valenciennes University, France.

Vanderdonckt J (1994) Guide ergonomique des interfaces homme-machine. Presses Universitaires de Namur, Namur, Facultés universitaires Notre-Dame de la Paix, Namur, Belgium

Vanderdonckt J (1999) Development milestones towards a tool for working with guidelines. Interacting With Computers 12(2):81-118

Vanderdonckt J, Coyette A (2007) Modèles, méthodes et outils de support au prototypage multi-fidélité des interfaces graphiques. Revue d'Interaction HommeMachine 8(1):91-123

Vanderdonckt J, Puerta AR (eds) (1999) Computer-Aided Design of User Interfaces II - Third International Conference of Computer-Aided Design of User Interfaces, Kluwer, Louvain-la-Neuve, Belgium

Ware C (2000) Information Visualization: Perception for Design. Morgan Kaufmann Publishers

van Wijk J (2005) The value of visualization. In: Silva C, Groeller E, Rushmeier H (eds) IEEE Visualization, IEEE Computer Society, pp 79-86

Winograd T (2001) Architectures for context. Hum-Comput Interact 16(2):401-419

Woodson W, Conover D (1964) Human Engineering Guide for Equipment Designers. University of California Press, Berkeley, California

Zhang L, Stoffel A, Behrisch M, Mittelstadt S, Schreck T, Pompl R, Weber S, Last H, Keim D (2012) Visual analytics for the big data era? A comparative review of state-of-the-art commercial systems. In: Visual Analytics Science and Technol- ogy (VAST), 2012 IEEE Conference on, IEEE, pp 173-182.. 